\title{
Structure-Formation and Vertical Turbulent Exchange in the Coastal Area of the Sevastopol Region
}

\author{
A.S. Samodurov, A.M. Chukharev, A.G. Zubov, O.I. Pavlenko \\ Marine Hydrophysical Institute, Russian Academy of Sciences,
Sevastopol, Russian Federation
e-mail: anatol_samodurov@mail.ru, alexchukh@mail.ru
}

With use of high-resolution probe-turbulimeter "Sigma-1" field data on the distribution of hydrophysical parameters in the upper layer of the sea around the Herakleian Peninsula (The Crimea) are collected. Based on the analysis of these data according to the previously developed methodology, the scales of turbulent patches in a stratified layer have been evaluated.On the basis of physic-climatic and hydrological conditions, it can be argued that the main source of turbulence here is the internal wave overturning which leads to the formation of turbulent spots. The coefficients of vertical turbulent exchange and the values of the dissipation rate of turbulent energy in the study area are calculated. Comparative analysis of data obtained in the spring and autumn seasons, showed different dependence of turbulent diffusion coefficients from the conditions of stratification. In the autumn, in the layers with small gradients of density coefficient is proportional to the buoyancy frequency, in the summer in the strongly stratified layer coefficient is already inversely proportional to this parameter. It is shown that the spatial distribution of diffusion coefficients reflects the characteristics of vertical exchange due to hydrologic structure and morphology of the bottom. The comparison of the results with our earlier "spectral" exchange model showed a good agreement of field measurements.

Keywords: probe-turbulimeter, microstructure, internal waves, shear instability, turbulent diffusion, energy dissipation, exchange models.

DOI: $10.22449 / 1573-160 X-2015-6-3-14$

(C) 2015, A.S. Samodurov, A.M. Chukharev, A.G. Zubov, O.I. Pavlenko

(C) 2015, Physical Oceanography

Introduction. One of the most important ecological characteristics for the intensively developed coastal basins is their self-purification ability. So far as the anthropogenic loads at the coastal area of the Crimean coast are rather appreciable [1], due to the increasing role of the Crimean and Sevastopol regions as the recreation areas, the research of circulation and vertical exchange features in the coastal waters becomes particularly actual.

In the spring-summer period, with the absence of winter convection, the turbulence becomes the main factor determining the vertical exchange in the sea upper layers. In a stably stratified ocean, away from the sharp frontal zones, the areas of double diffusion mechanisms evident manifestation and so on, the main source of turbulence is a shear instability mechanism in the field of quasi-inertial internal waves (IW) [2]. A considerable number of works is devoted to the evaluation of this mechanism contribution to the vertical exchange. The basic direction of this research is usually associated with the search for the power dependence of energy dissipation rate and vertical turbulent diffusion coefficient from the buoyancy frequency. This allows us to obtain the vertical distribution of the diffusion coefficient, knowing the buoyancy frequency change with the depth.

During the search for such theoretical correlations the different approaches are applied. For example, in the works [3 - 5] the analytical and numerical models of internal waves, considering the mechanisms of non-linear energy transfer by the Garrett - Munk spectrum to the low-frequency waves and small vertical scale waves are used. As a result, the authors obtained a quadratic dependence of the energy dissipation rate from the buoyancy frequency. 
In the work [6] the stationary equation of turbulent energy balance was used. As the result, for the narrow-band frequency spectrum of internal waves the linear dependence of energy dissipation rate was obtained from the buoyancy frequency, and for the wide-band spectrum the corresponding exponent appeared to be 1.5.

In the work [7], where the Garrett - Munk spectrum considering the dissipative loss was taken as a basic, the quadratic dependence of required function from the buoyancy frequency was obtained. This model is considered to be the most appropriate for the given conditions. It should be noted that each of the given models offers a single power law for the entire stratified layer.

The purpose of this work is the determination of vertical turbulent exchange regional features in the Black Sea upper stratified layer near the shelf and Heraclean Peninsula continental slope, and also the verification of the exchange model. Besides, we have been used two own original developments:

- semi-empirical model of turbulent diffusion coefficient and dissipation rate calculation, depending on the buoyancy frequency for the IW breaking mechanism by the measured vertical profiles of temperature pulsations. This model is a practical calculation method of the values observed in reality;

- modified theoretical model of the required parameters dependence on the buoyancy frequency, which is based on the advanced IW climatic spectrum model and doesn't require the measurements data [8] involvement for the univariate spectra reconstruction. Unlike the previous models, in the modified variant there are proposed different power dependences for the upper und lower stratified layers in the natural basins, backed up by the analysis of the published field measurements data [9]. Such model in comparison with the others known experimental and theoretical dependences is more universal.

Measurements. The field measurements of pulsating characteristics were performed by the measuring complex Sigma-1 [10], meant for research the microstructure and turbulent exchange in the sea upper layer. The exterior view of the complex is given in Fig. 1 and its main technical characteristics - in the table.

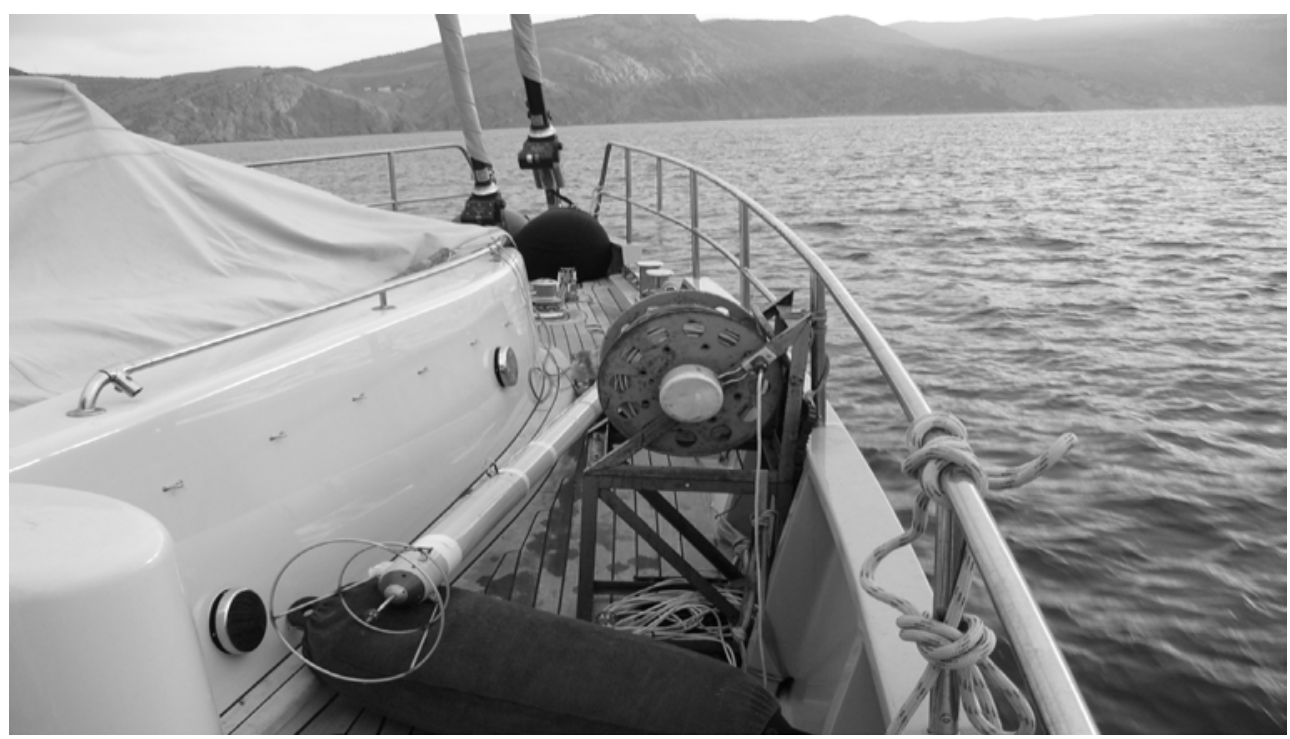

Fig. 1. Measuring complex Sigma-1 on board of R/V Nikolayev, November 28, 2014 
Technical characteristics of Sigma-1 measuring complex

\begin{tabular}{|c|c|c|c|c|}
\hline Measuring parameters & Range & Resolution & Accuracy & $\begin{array}{l}\text { Discreteness of } \\
\text { measurements }\end{array}$ \\
\hline $\begin{array}{l}\text { Three components of pulsation } \\
\text { velocity vector, } \mathrm{m} / \mathrm{s}\end{array}$ & \pm 2 & $10^{-3}$ & $\pm 10 \%$ & $\begin{array}{l}100 \mathrm{~Hz} \text { by all the } \\
\text { channels }\end{array}$ \\
\hline Temperature, ${ }^{\circ} \mathrm{C}$ & $0-30$ & 0.001 & $\pm 5 \%$ & \\
\hline Conductivity, relative units & $0-0.9$ & $2.5 \cdot 10^{-5}$ & $\pm 5 \%$ & \\
\hline $\begin{array}{l}\text { Three components of linear } \\
\text { accelerations, } \mathrm{m} / \mathrm{s}^{2}\end{array}$ & \pm 20 & 0.002 & 0.002 & \\
\hline Roll and pitch of the device, ${ }^{\circ}$ & \pm 20 & 0.01 & \pm 1 & \\
\hline Azimuth angle of the device, ${ }^{\circ}$ & $0-360$ & 10 & \pm 5 & \\
\hline Pressure, MPa & $0-6$ & $5 \cdot 10^{-4}$ & $\pm 1 \%$ & \\
\hline
\end{tabular}

The experimental work had been carrying on from the board of R/V Nikolayev at November 27 - 28, 2014. The fine structure of current velocity fields, temperature and conductivity data acquisition was performed by probing at the research area stations from the surface to $50-130 \mathrm{~m}$ depending on the place depth. The probing was performed in a free fall mode with $\sim 0.7 \mathrm{~m} / \mathrm{s}$ speed. The vertical deviation of the probe during the steady motion didn't exceed $1^{\circ}$, and the frequency of these oscillations was situated generally out of the frequency range using for the analysis. Thus, natural vibrations of the carrier didn't substantially affect the obtained information about turbulent pulsations. Nevertheless, to avoid a possible natural vibrations manifestation in the analyzed data, during the analysis the preference was given to the scalar value, namely temperature pulsations. Fig. 2 shows the scheme of hydrological stations, performed during the experiment.

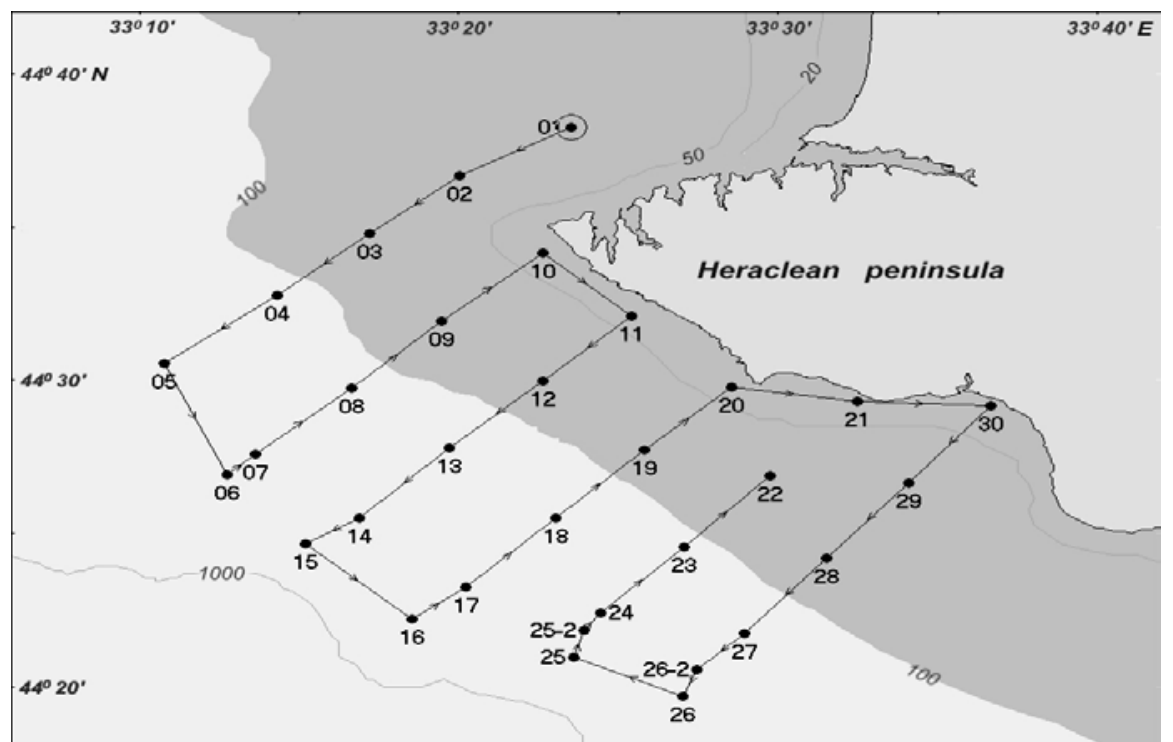

Fig. 2. The scheme of the measurements performed in the research area around the Heraclean peninsula at November 27 - 28, 2014

PHYSICAL OCEANOGRAPHY NO. 6 (2015) 
It is known [11] that one of the main turbulence generation mechanisms in the stratified layers is the internal waves overturning. Such events lead to the turbulent patches formation, where an intensive mixing resulting in the smoothing of hydrological characteristics within the patch limits takes place. In the density profiles that manifests as zones with the constant density by depth (so-called "steps"). In Fig. 3 a typical density distribution profile obtained during the experiment, where such zones are noticeable, is shown.

The methodology of the turbulent patches scales evaluation is the following. In the density profiles the segments with the approximately constant value of buoyancy were selected $N=\sqrt{\frac{g}{\rho_{0}} \frac{d \rho}{d z}}$ (Fig. 4), where $\rho$ - density; $g$ - free fall acceleration. The vertical spectra of temperature pulsation gradients in the wave number space were calculated according to them. The local minimum, which corresponds to the characteristic turbulent patches scale in the given layer, was situated at the spectra. The typical spectrum of temperature gradient pulsation is given in Fig. 5, where such a local minimum is distinct.

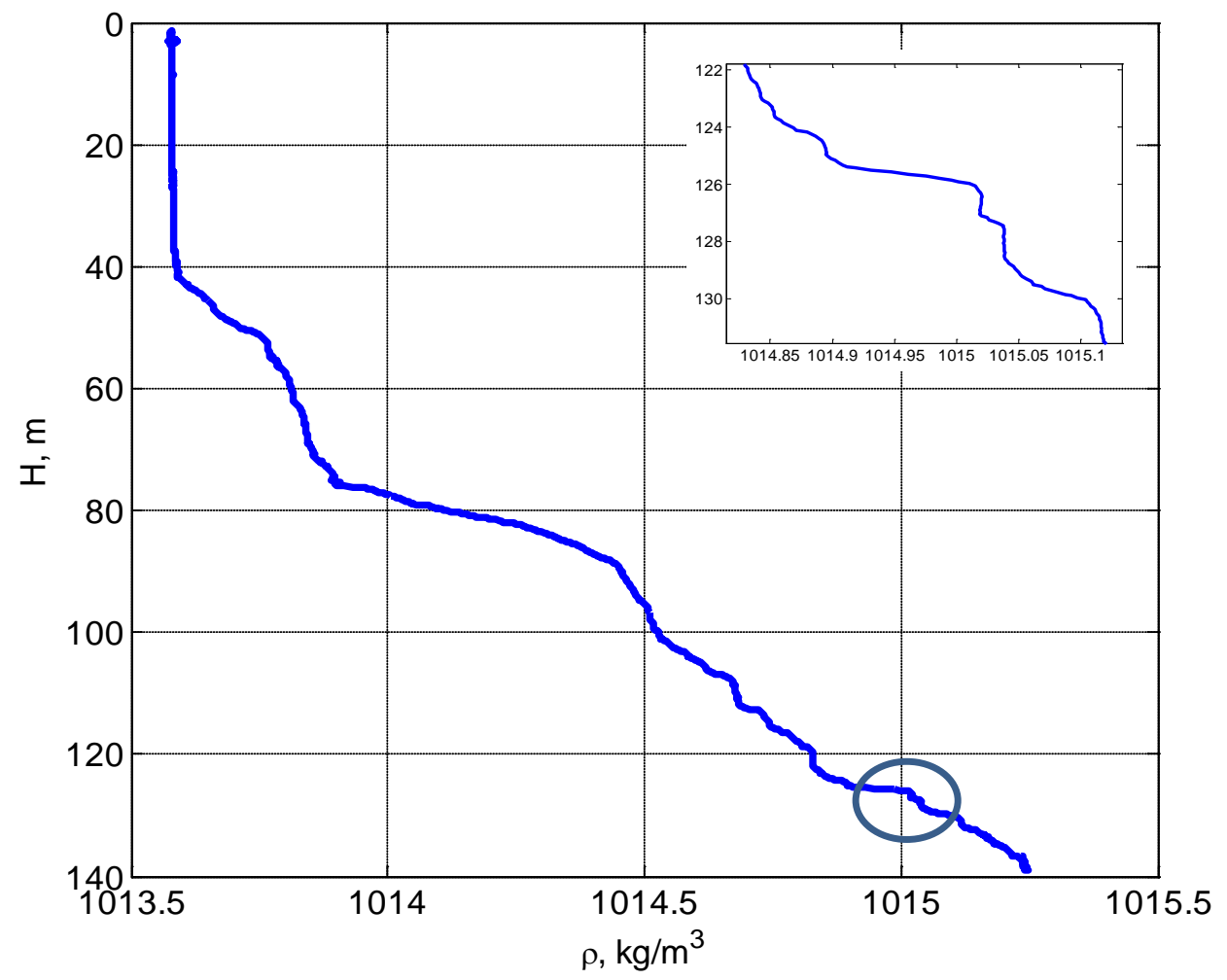

Fig. 3. The manifestation of turbulent patches at the density profiles (in the insert the enlargement is shown) 

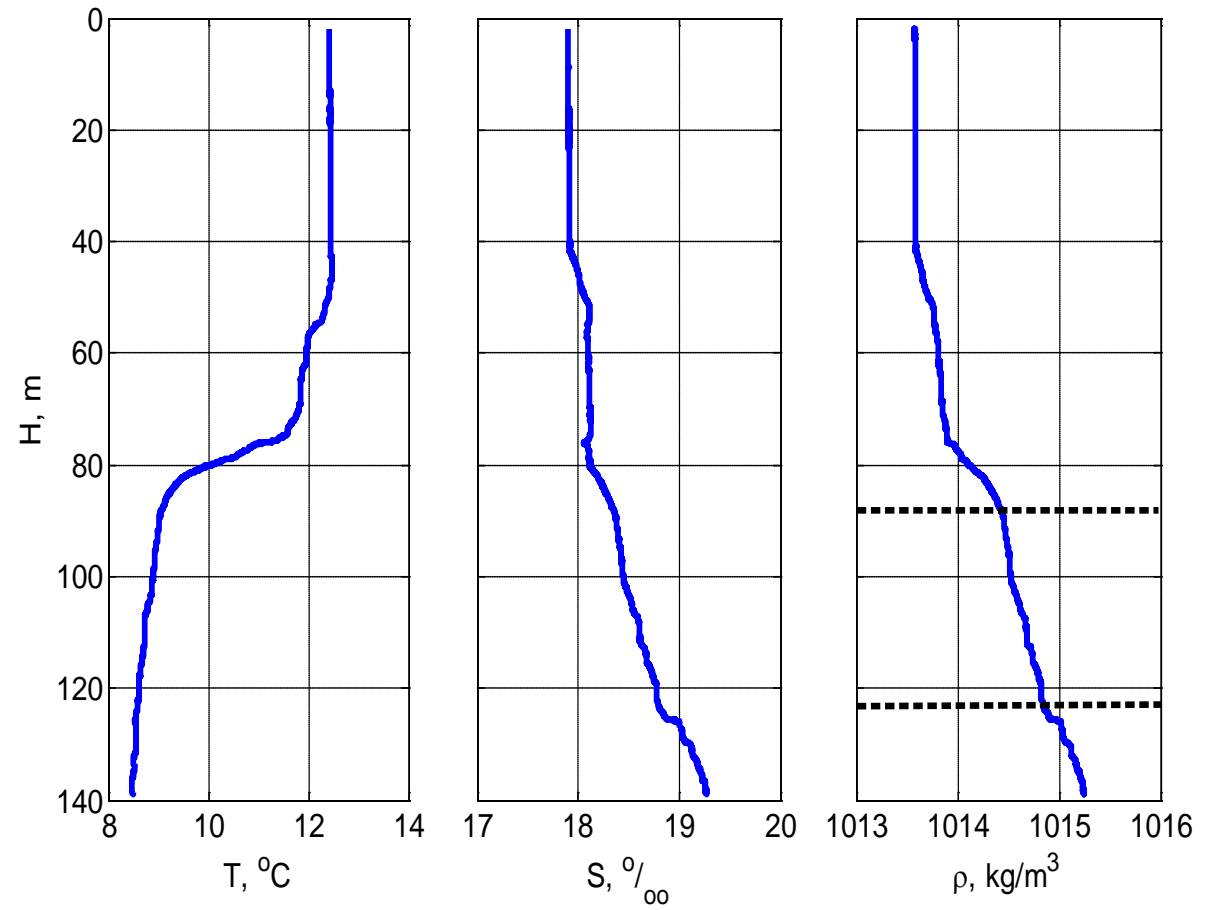

Fig. 4. Typical profiles of temperature, salinity and density distribution. The range of depths with the approximately constant density gradient, where the vertical spectra of temperature gradients and turbulent patches scales are calculated, was signed by horizontal lines

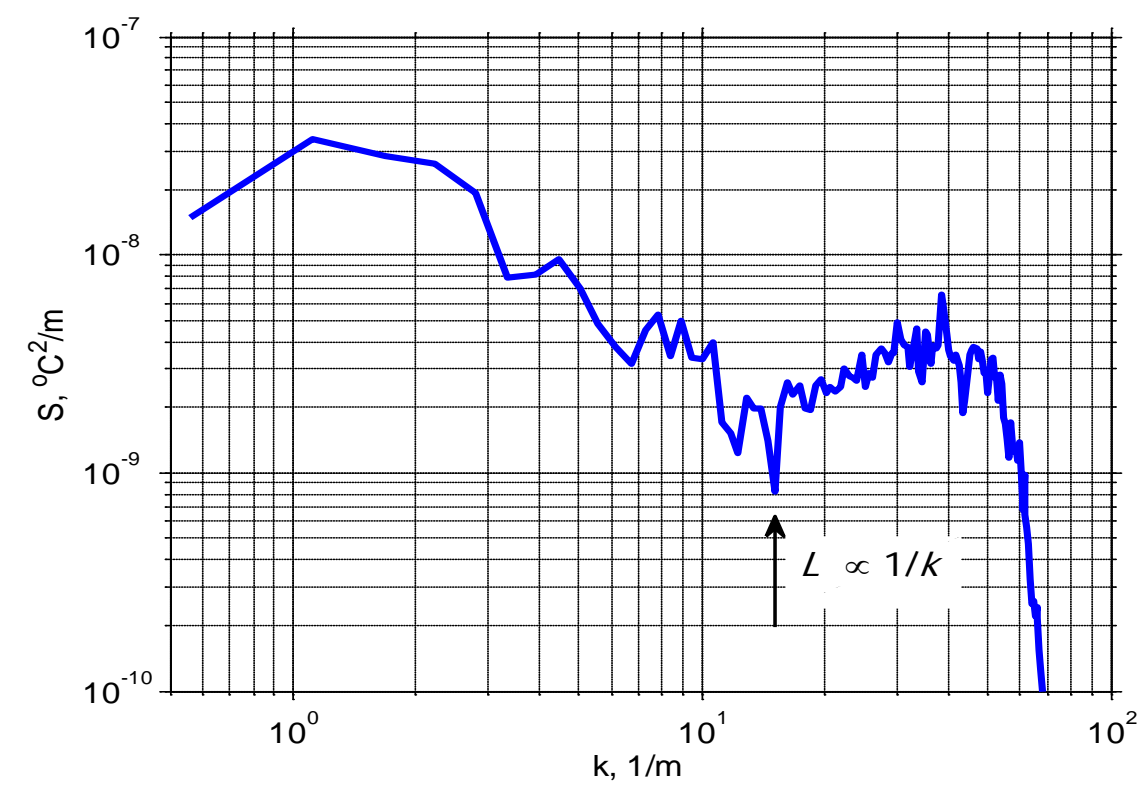

Fig. 5. The spectrum of temperature gradient pulsations at the $51-74 \mathrm{~m}$ depths range according the measurements of station 26-2 (November, 28, 2014). Minimum at the spectrum corresponds to the turbulent patches scale

PHYSICAL OCEANOGRAPHY NO. 6 (2015) 


\section{The exchange intensity comparison in spring and summer seasons.}

According to the current conceptions, the key role of vertical mixing in stratified layers belongs to the internal waves $[11,12]$. As it was mentioned in the introduction, the main mechanism responsible for the mixing and maintaining of the vertical turbulent diffusion is local instability and the breaking of the quasihorizontal shear currents generated by inertial-gravity IW [2]. It is the mentioned mechanism, which makes the main contribution to the vertical turbulent exchange. Considering this fact, in the work [13] a semi-empirical dependence model of energy dissipation rate $\varepsilon$ and vertical turbulent diffusion coefficient $K$ on the local buoyancy frequency $N$ was developed. For evaluating of these variables the concept of typical turbulent patches scale determining from the experimental observations is used. The method of the patch scale $L$ determination, depending on the buoyancy frequency is based on the energetic approach to the description of turbulent patches according to the relationship from the work [13]:

$$
L \approx 2.3 \varepsilon_{S}{ }^{1 / 3} N^{-1},
$$

where $\varepsilon_{S}=\varepsilon L$ is energy dissipation rate per area unit ( $\varepsilon$ is per volume unit).

As the result of the probing data representative array analysis in the seasonal thermocline of the ocean [13] the empirical dependence was obtained:

$$
L=D N^{-1} \mathrm{~m} \text {, }
$$

where the dimension of the buoyancy frequency is $[N]=$ cycle/h;

proportionality coefficient $D \approx 1.4 \mathrm{~m} \cdot$ cycle/h.

Using the known Osborne relation $K \cong 0.2 \varepsilon N^{-2}$ [14] and considering (1) we are able to obtain the following relationships for $\varepsilon$ and $K$ :

$$
\begin{gathered}
\varepsilon \approx 4.3 \cdot 10^{-10} D^{2} N \mathrm{~m}^{2} / \mathrm{s}^{3}, \\
K=4.8 \cdot 10^{-5} D^{2} N^{-1} \mathrm{~m}^{2} / \mathrm{s} .
\end{gathered}
$$

On the basis of experimental results [15 - 17] it was determined that the value of the coefficient $D$ could vary depending on the stratification type and the conditions of IW distribution. In the open sea, in the upper stratified layer its value amounts approximately 1.4 and in the shelf and continental slope conjugation zone it could increase up to 4.2 .

During the practical use of such model the dependence $L(N)$ was assessed experimentally according to the array of vertical probing data as it was described above. In Fig. 6 all the possessed empirical arrays of calculations $L(N)$ in the researched layer are represented [15 - 17].

These results were obtained according to the data of probing using Sigma-1 probe in the shelf and continental slope of the Black sea conjugation zone in 2004 - 2014. The discussed calculations, performed on the basis of the measurements in November, 2014, are marked by red square marks.

The straight lines in Fig. 6 are the empirical power approximations of dependence $L(N)$ : 1 - for upper stratified layer of the open parts of the ocean described in the work [13] and the analogous layer in the Black sea from the works $[13,18] ; 2,3$ and 4 - for upper stratified layer of the Black Sea in the shelf and continental zone conjugation zone. 


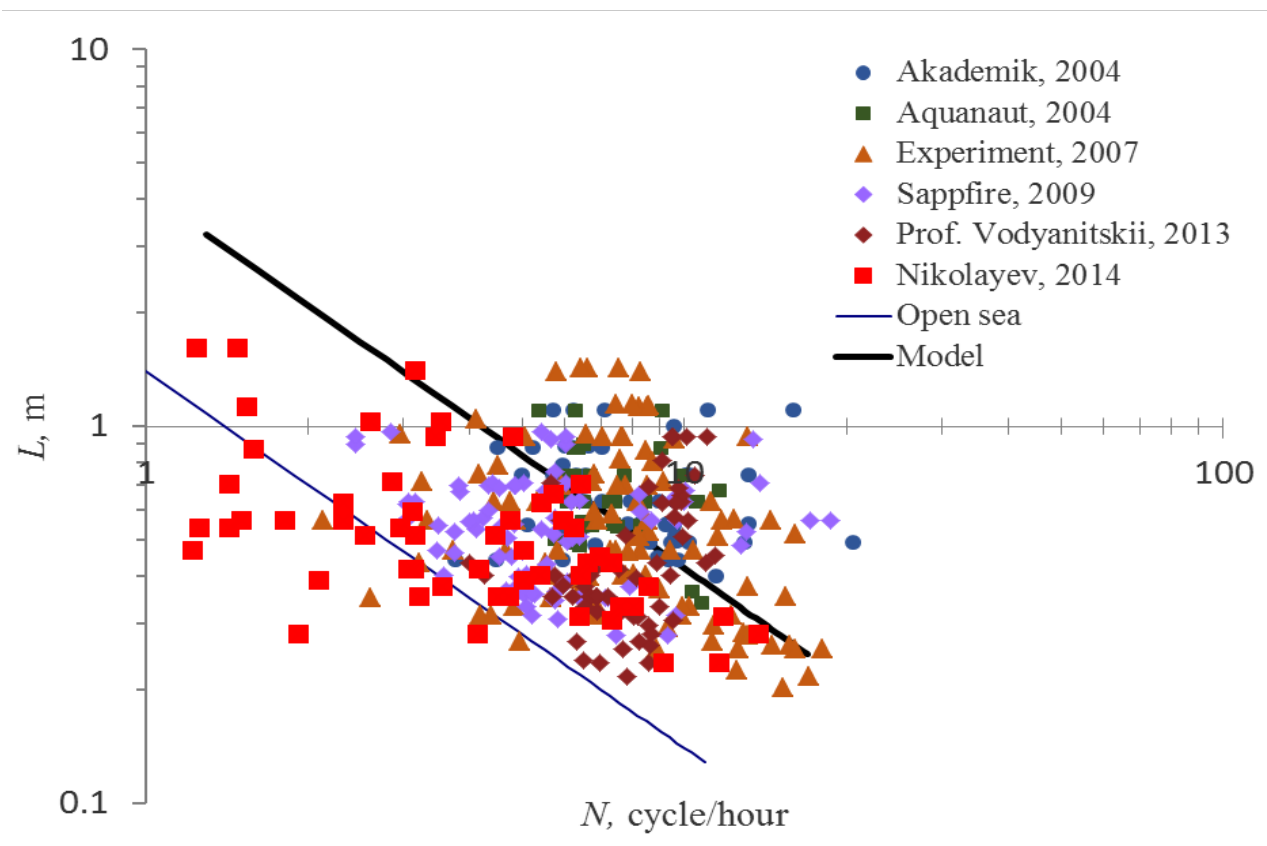

Fig. 6. Empirical arrays of the dependence $L(N)$ calculations under the long-term array of probing data using the cyclic frequency $N$. In the right upper corner the first six inscriptions are the $\mathrm{R} / \mathrm{V}$ names and the years when the expeditions had been performed. The marks denote the experimental values; line 1- is semi-empirical dependence for the open part of the sea under the results of the work [13]; line 2 - is the dependence for the shelf and continental slope conjugation zone under the results of spring-summer observations 2004 - 2013; line 3 - is the dependence under the measurements data in November, 2014 for the layers with small density gradients

The required dependences 1 and 2 have the following form: $L \cong 1.4 N^{-1}$ and $L \cong 4.2 N^{-1}$ respectively. Besides, the numerical factors in the expressions (3) and (4) for the values $\varepsilon$ and $K$ in the buoyancy frequency range $5-10$ cycle/h differ almost at the order of magnitude.

Because of the fact that the variation range of $N$ in the upper layer of the Black Sea considering areas is relatively small, and data scattering of $L(N)$ there is sufficiently great, to determine the power dependence $L(N)$ the long-term average power dependence $N(z)$ for the upper stratified layer of the Black Sea, calculated in the work [8], was used

$$
N \propto 1 / z
$$

where $z$ - is applicate.

As it could be seen from Fig. 6, the measurement results, obtained in the late autumn, showed a significant difference from the results obtained in spring and summer. In the scale range $N=5-10$ cycle/h the difference is just quantitative i. e. $\varepsilon$ and $K$ levels appeared to be somewhat lower (2 and 3 lines) and in the lowfrequency zone (line 4 ) the value $L$ is practically independent from $N$. It means that the mentioned dependence approximates $L=$ const relation. In the "warm" period the range of values $N<5$ cycle/h in the upper stratified layer is small and we were not able to assess such features before. 
The dependence of vertical turbulent diffusion coefficient $K$ on the value of local vertical density gradient in the upper stratified layer in the conjugation zone for the "cold" season could be expressed the following way:

$$
K \propto N
$$

for the low-gradient range,

$$
K \propto N^{-1}
$$

for the high-gradient range.

The difference in the coefficient $K$ dependence on the buoyancy frequency $N$ is also observed in the ocean [9]. The obtained result could be explained on the basis of "spectrum" model of vertical turbulent diffusion from the work [8], which is verified at the great array of different field measurements [9]. The exchange model is based on the original model of IW climatic spectrum from the work [13] considering the energy dissipation obtained from the breakings in the wave field. The effect of density gradient value at the wave number range, where could exist the IW taking into account their dissipation losses, is considered in the model

Thus, different $K$ dependences from the stratification for different layer structure take place. For the upper stratified layer with higher $N$ gradients by depth the model relation is given by

$$
K \propto N|\partial N / \partial z|^{-1} .
$$

Considering the long-term $N$ dependence from the depth (5) we'll obtain the expression for $K$ in the upper stratified layer:

$$
K \propto N^{-1} .
$$

For the lower stratified layer with the smooth $N(z)$ change the following model dependence is implemented:

$$
K \propto N .
$$

It is obvious that depending on the structure of local vertical density gradient the analysis of the given measurements by the method [13] and the theoretical model [8] lead to the same results. It is true under the condition of the models application to the same area where a key mechanism of vertical diffusion are the breakings in the field of low-frequency internal waves, and the frequency distribution of buoyancy satisfies to expression (5).

Fig 7 clearly illustrates the difference in the stratification parameters, which shows the distribution of the density parameter in the sectional view performed at the stations 26 - 30 (Fig. 2). By analogy with the model [8] the stratified layer in the studied case can be divided into two parts - the upper, weakly stratified part, and the lower, relatively strong stratified part. The boundary between them passes approximately by the isopicnic value 13.7. It should be noted that the described physics of the mixing processes retains even in the presence of alongshore currents, such as the Main Black Sea Current [15]. 


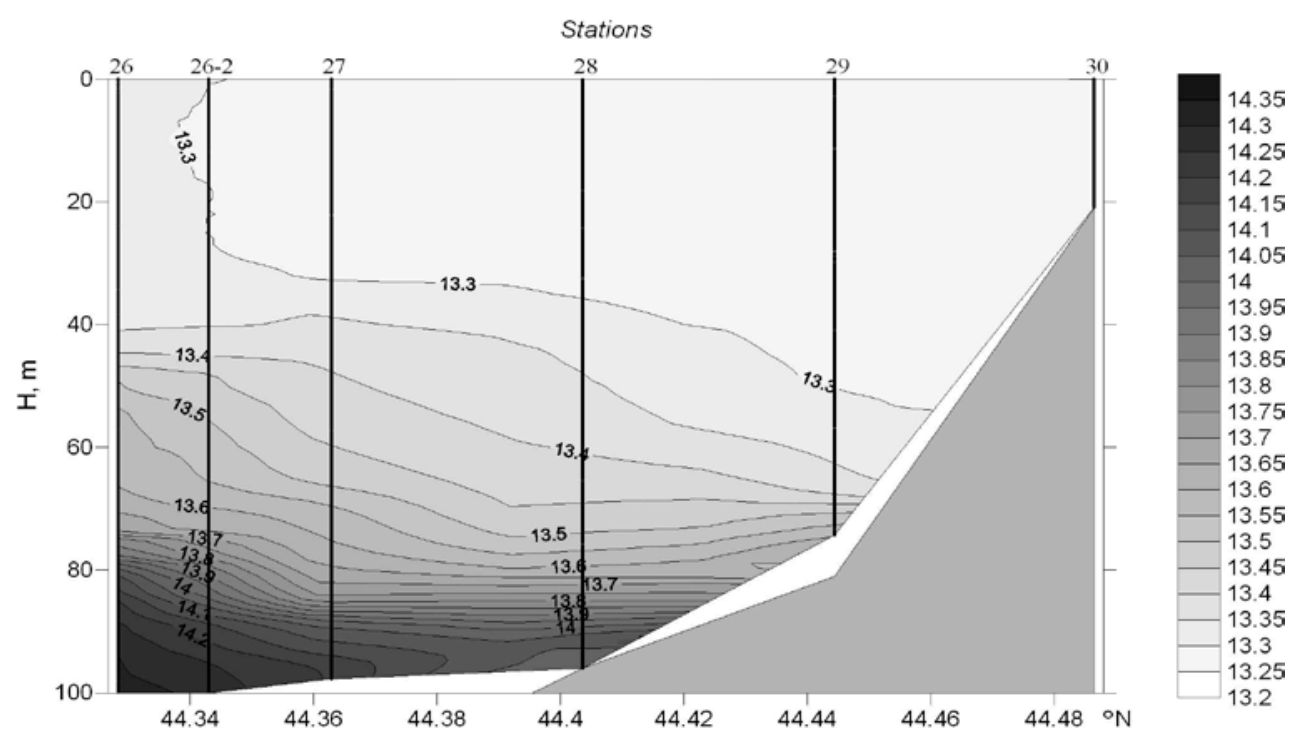

Fig. 7. The distribution of the density parameter on the section across the isobaths (stations $26-30$ )

In this case, the weakly gradient layer is located above a strongly stratified layer, unlike the situation considered in the model [8], where it is located below. Nevertheless, the stratification conditions seem to play the major role in the dynamics of IW propagation and breaking. With the density gradient decrease in the autumn-winter period, the IW dynamics in the Black Sea upper layer (or rather in its surficial part (Fig. 7)) reaching a certain threshold state passes into the "main pycnocline mode" (under the article [8] terminology).

Thus, the verification of "spectral" model showed that the weakly stratified layers located above or below the strongly stratified layers have the same local dynamics, which determines the mixing and vertical exchange $(K \propto N)$ i. e. this result extends the scope application of the "spectral" model [8].

Structural features of the studied characteristics in the upper weakly gradient layer. An example of vertical turbulent diffusion coefficient calculation at the research area in the $30-80 \mathrm{~m}$ depth range is represented in Fig. 8. In this case the coefficient was calculated using the relation (10) because in the depth range where it was determined the typical turbulent patches scale $L$ was practically independent from the local buoyancy frequency (Fig. 6). In general, the distribution of $K$ on a horizontal plane represents the joint influence of hydrological structure and sea bottom. An important feature of the Black Sea shelf and continental slope conjugation zone is an existence of a sharp depth drop where the intensity of turbulent patches formation increases $[15,16]$, which leads to the noticeable increasing of the diffusion coefficient and the energy dissipation rate. In Fig. 8 this effect (the dark area, characterized by high values of the diffusion coefficient) is observed between the shelf area and the open sea, though it doesn't entirely corresponds with the sharp depth drop zone. 


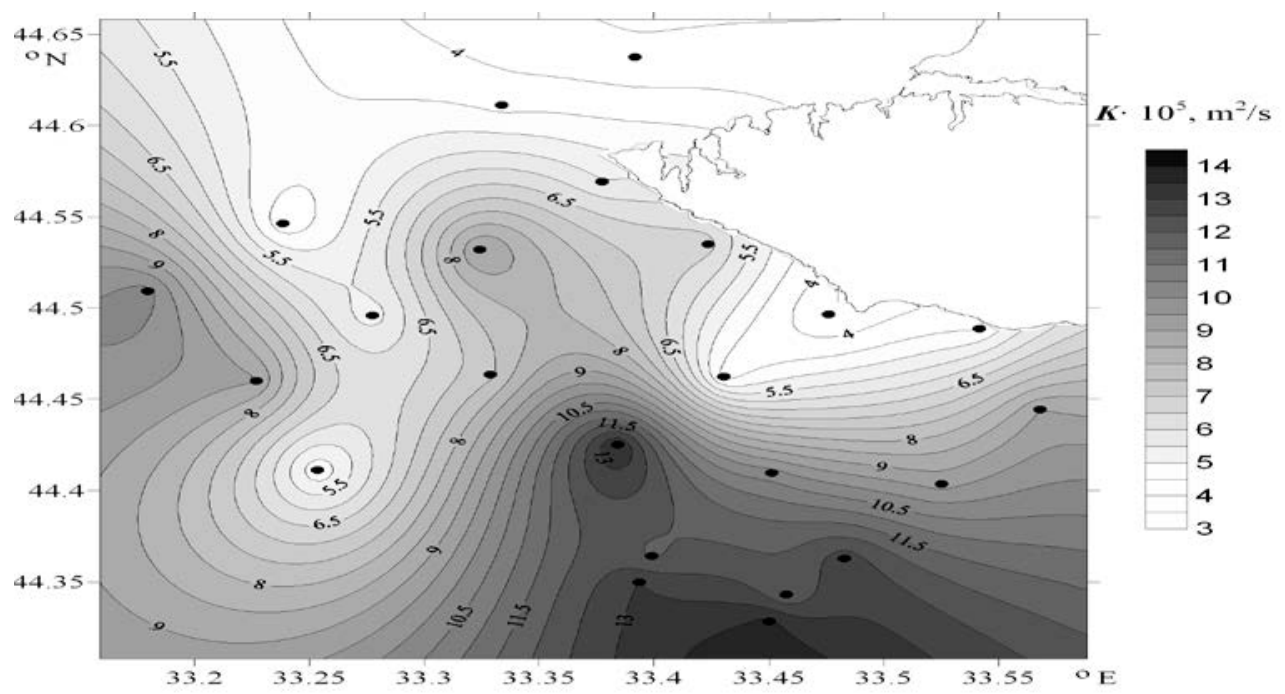

Fig. 8. The spatial distribution of the vertical turbulent diffusion in the upper stratified layer under the results of measurements carried out on November 27 - 28, 2014 (the stations are marked by dots)

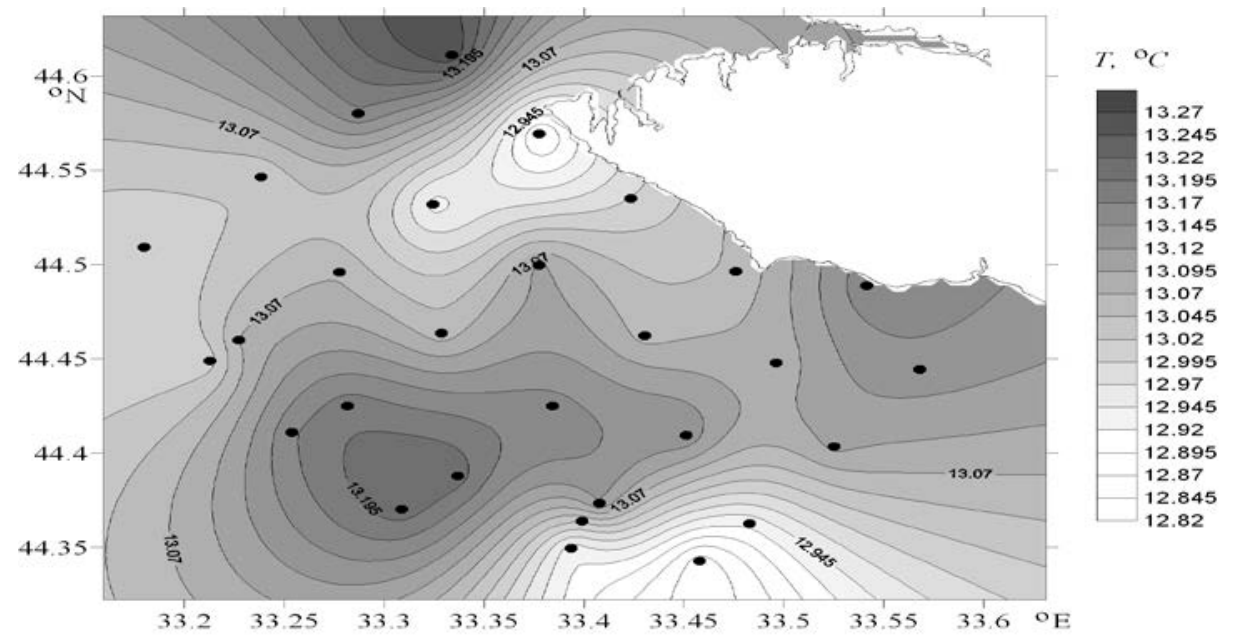

Fig. 9. The temperature distribution at $30 \mathrm{~m}$ level under the results of the measurements carried out on November 27 - 28, 2014

Special attention should be paid to the salinity and temperature abnormal zone detected near the Chersonesus cape (near the station 10 in the Fig. 2). The presence of this formation from the surface and down to approximately 80 m levels seems to appear due to the strong wastewater discharge, because the wastewaters have lower salinity and temperature. Fig. 9 shows the temperature distribution in this area at 30 $\mathrm{m}$ level where the discharge spot has an intrusion form, which spreads from the coastal area to the sea. The probability of such form of the spots is confirmed by the Fig. 10 where the potential temperature distribution is represented at the section, which crosses the revealed structure. Colder intrusions from the coast penetrate into the relatively warm water mass located in the centre of the section. Thus, the area of liquid formed under the influence of cold desalinated water of 
discharge is divided into the upper plume with the small intrusions and the separated lower intrusion (or the "classic" plume) flowing down the slope (in the right bottom corner of Fig. 10, $80 \mathrm{~m}$ level). Such situations should be considered during the exchange mechanisms assessment in the shelf and continental slope conjugation zone.

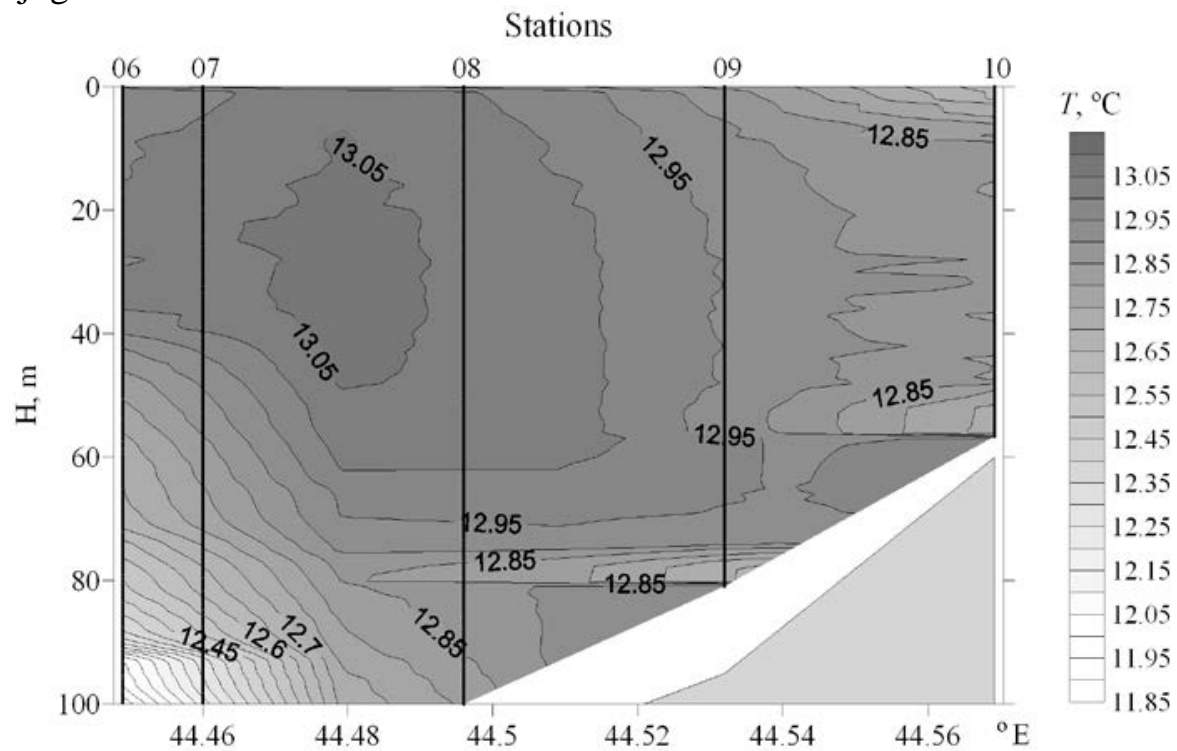

Fig. 10. The distribution of the potential temperature at the section (stations 6 -10, Fig. 2)

Conclusions. The performed research showed the presence of the vertical exchange mode features in the coastal area of the Herakleian Peninsula, which is conditioned by the bottom topography and hydrological structure forming in accordance with the season. The model dependences of vertical turbulent diffusion coefficient on the buoyancy frequency (9) and (10) satisfactorily describe the obtained experimental values in the layers with high and low density gradients respectively.

Acknowledgements. The research was carried out in Marine Hydrophysical Institute RAS under the sponsorship of the Ministry of Education and Sciences of the Russian Federation within the framework of the Federal Target-Oriented Program "Research and Development in Priority Development Directions of the Scientific-Technological Complex in the Russian Federation 2014 - 2020” (unique project code RFMEFI57714X0110) and also under the sponsorship of RFBR "The South of Russia” project No. 14-45-01545.

\section{REFERENCES}

1. Sovga, E.E., Pasynkov, A.A., Andreeva, O.A., 2011, "Ecologicheskoe sostoyanie pribrezhnomorskikh rayonov Kryma [Ecological condition of the coastal areas of the Crimea]", Ekologicheskaya bezopasnost' pribrezhnoy i shel'fovoy zon $i$ kompleksnoe ispol'zovanie resursov shel'fa, iss. 25, vol. 1, pp. 169-180 (in Russian).

2. Wunsch, C., Ferrari, R., 2004, "Vertical mixing, energy, and the general circulation of the ocean”, Ann. Rev. Fluid Mech., vol. 2004, pp. 281-314.

3. McComas, C.H., Muller, P., 1981, "The dynamic balance of internal waves”, J. Phys Oceanogr., vol. 11, no. 7, pp. 970-986. 
4. Henyey, F.S., Wright, J., Flatte, S.M., 1986, "Energy and action flow through the internal wave field: An eikonal approach”, J. Geophys. Res., vol. 91, pp. 8487-8495.

5. Winters, K.B., D’Asaro, E.A., 1997, “Direct simulation of internal wave energy transfer”, $J$. Phys. Oceanogr., vol. 27, no. 9, pp. 1937-1945.

6. Gargett, A.E., Holloway, G., 1984, "Dissipation and diffusion by internal wave breaking”, $J$. Mar. Res., vol. 42, no. 1, pp. 15-27.

7. Gregg, M.C., 1989, “Scaling turbulent dissipation in the thermocline”, J. Geophys. Res., vol. 94, no. 7, pp. 9686-9698.

8. Samodurov, A.S., Globina, L.V., 2011, "Dissipatsiya energii i vertikal'nyy obmen v stratifitsirovannykh basseynakh za schet sdvigovoy neustoychivosti $v$ pole kvaziinertsionnykh vnutrennikh voln [Energy dissipation and vertical change in stratified basins at the expense of the shear instability in the field of quasi-inertial internal waves]", Morskoy gidrofizicheskiy zhurnal, no. 6, pp. 16-27 (in Russian).

9. $\quad$ Samodurov, A.S., Globina, L.V., 2012, “Zavisimost' skorosti dissipatsii turbulentnoy energii i vertikal'nogo obmena ot stratifikatsii po obobshchennym eksperimental'nym dannym (sravnenie s sushchestvuyushchimi modelyami) [Dependence of turbulent energy dissipation rate and vertical exchange from stratification according to the generic experimental data (comparison with the existing models)]”, Morskoy gidrofizicheskiy zhurnal, no. 6, pp. 17-34 (in Russian).

10. Samodurov, A.S., Dykman, V.Z., Barabash, V.A. [et al.], 2005, “Izmeritel'nyy kompleks «Sigma-1» dlya issledovaniya melkomasshtabnykh kharakteristik gidrofizicheskikh poley $v$ verkhnem sloe morya ["Sigma-1" measuring complex for the investigation of small-scale characteristics of hydrophysical fields in the upper layer of the sea]", Morskoy gidrofizicheskiy zhurnal, vol. 15, no. 5, pp. 311-322 (in Russian).

11. Kamenkovich, V.M., Monin, A.S., 1978, Okeanologiya. Fizika okeana, Moscow, Nauka, vol. 2, Gidrodinamika okeana, 455 p. (in Russian).

12. Hebert, D., Moum, J.N., Paulson, C.A. [et al.], 1992, "Turbulence and internal waves at the equator. II. Details of a single event”, J. Phys. Oceanogr., vol. 22, no. 11, pp. 1346-1356.

13. Samodurov, A.S., Lyubitskii, A.A., Panteleev, N.A., 1994, "Vklad oprokidyvayushchikhsya vnutrennikh voln $v$ strukturoobrazovanie, dissipatsiyu energii $i$ vertikal'nuyu diffuziyu $v$ okeane [Contribution of the overturning internal waves in the structure formation, energy dissipation and vertical diffusion in the ocean]”, Morskoy gidrofizicheskiy zhurnal, no. 3, pp. 14-27 (in Russian).

14. Osborn, T.R., 1980, "Estimations of local rate of vertical diffusion from dissipation measurements”, J. Phys. Oceanogr., vol. 10, no. 1, pp. 83-89.

15. Samodurov, A.S., Chukharev, A.M., Nosova, A.V. [et al.], 2013, "Intensifikatsiya vnutrennikh voln $v$ zone sopryazheniya shel'fa i kontinental'nogo sklona kak faktor intensifikatsii vertikal'nogo obmena [Intensification of the internal waves in the shelf and continental slope conjugation zone as a vertical exchange intensification factor]”, Fundamental'naya i prikladnaya gidrofizika, vol. 6, no. 2, pp. 12-24 (in Russian).

16. Samodurov, A.S., Chukharev, A.M., 2008, "Eksperimental'naya otsenka koeffitsienta vertikal'nogo turbulentnogo obmena $v$ stratifitsirovannom sloe Chernogo morya $v$ okrestnosti svala glubin [Experimental estimation of the coefficient of vertical turbulent exchange in a stratified layer of the Black Sea near the continental slope]”, Morskoy gidrofizicheskiy zhurnal, vol. 18, no. 6, pp. 308-318 (in Russian).

17. Samodurov, A.S., Chukharev, A.M., Kul'sha, O.E., 2015, “Rezhimy vertikal'nogo turbulentnogo obmena $v$ verkhnem stratifitsirovannom sloe Chernogo morya $v$ rayone Gerakleyskogo poluostrova [Vertical turbulent exchange modes in the upper stratified layer of the Black Sea in the area of the Heraklean Peninsula]”, Protsessy v geosredakh, no. 3, pp. 6369 (in Russian).

18. Ivanov, L.I., Samodurov, A.S., 2001, "The role of lateral fluxes in ventilation of the Black Sea”, J. Mar. Syst., vol. 31, no. 1-3, pp. 159-174 (in Russian). 